\title{
Embedded Journalists or Empirical Critics? The Nature of The "Gaze" in Bioethics
}

\author{
Michael A. Ashby • Bronwen Morrell
}

Published online: 19 October 2018

(C) Journal of Bioethical Inquiry Pty Ltd. 2018

\begin{abstract}
Keywords Critical bioethics · Dualisms · Interdisciplinarity $\cdot$ Holism $\cdot$ Collective representation
\end{abstract}

Four times a year we publish papers that are often technical in their consideration of the ethical aspects of complex bioscience and health issues. Bioethics scholars are increasingly specialists in very specific niche areas as it is impossible to do the work without understanding the science nor is it possible to cover the whole field for one particular scholar or craft group. Their "take" on a given subject is determined by their parent discipline (ethics, sociology, law, etc), coupled with content knowledge and understanding. This raises the question of the "nature of the gaze" of the thinker/writer, because the process of understanding may require a relationship with the subject and

\section{A. Ashby $(\bowtie)$}

Palliative Care Service, Royal Hobart Hospital, Tasmanian Health Service, and School of Medicine, Faculty of Health Sciences, University of Tasmania, 1st Floor, Peacock Building, Repatriation Centre, 90 Davey Street, Hobart, TAS 7000, Australia

e-mail: michael.ashby@ths.tas.gov.au

\section{B. Morrell}

Sydney Health Ethics, Faculty of Medicine and Health, University of Sydney, Level 1, Medical Foundation Building, K25, Sydney, NSW 2006, Australia

e-mail: bronwenmorrell@gmail.com its researchers, whereby the bioethicist becomes "embedded" in the area and indeed may achieve, or strive for, credibility and perhaps respect from the practitioners concerned and within the scientific community. Indeed, if this is lacking, it is unlikely that the bioethics will be taken seriously within the field concerned. But the bioethicist is also writing in order to open the subject up to scrutiny and is responsible for a far broader task-that of revealing and analysing the issues for the rest of the community, both local and global. So the gaze, and its potential dualities and conflicts of interest are important and worthy of examination. Is the bioethics scholar an "embedded" correspondent, like a journalist in a combat zone, or a participant observer even, such as in anthropological fieldwork? The comparison to journalism is potentially interesting as it may then be fruitful to examine ethics in journalism and see where the parallels might be. Protection of sources is not such an issue for bioethics but a desire to pursue the truth most certainly is. This of course presupposes the notion that there is an object of truth to be arrived at. So much ethical discourse is inevitably mixed up with subjective sense impressions, emotions, and beliefs which are not so much to be stripped away to reveal an objective truth or reality but rather to be understood and honoured as part of the lived human experience.

The danger of the journalist embedded within the military is that his or her objectivity may be compromised or censored and that they "go native" and are 
recruited to the views of the military. This seems to be the issue that is being tackled in so-called "critical" bioethics, explored by writers such as Richard Twine:

Here this concept is principally defined in terms of the three features of interdisciplinarity, selfreflexivity and the avoidance of uncritical complicity. In a partial reclamation of the ideas of V.R. Potter, it is argued that a critical bioethics requires a meaningful challenge to culture/nature dualism, expressed in bioethics as the distinction between medical ethics and ecological ethics. Such a contesting of the "bio" in bioethics arrests its ethical bracketing of environmental and animal ethics. Taken together, the triadic definition of a critical bioethics offered here provides a potential framework with which to fend off critiques of commercial capture or of being "too close to science" commonly directed toward bioethics. (Twine 2005, 285)

Adam Hedgecoe sees critical bioethics as "building" on the sociological tradition in bioethics, evidenced in the work of pioneers such as Fox, Hoffmaster, and Boff:

Critical bioethics requires bioethicists to root their enquires in empirical research, to challenge theories using evidence, to be reflexive and to be sceptical about the claims of other bioethicists, scientists and clinicians. The aim is to produce a rigorous normative analysis of lived moral experience. (Hedgecoe 2004, 120)

Is this in fact a dichotomy or a nested set of values that need not be in conflict? On the one hand, there is a methodological claim at stake. It is clear that a number of separate disciplines, with large discrete literatures, for which long academic apprenticeships are necessary, and from which the uninitiated to some degree excluded, contribute to the field of bioethics. These include philosophy, sociology, psychology, and anthropology. However, the issues of bioethics are played out across all science and health disciplines and need to be both seen and "socialized" throughout the community. So the conversation cannot be solely in the academy or in any one area of it, from which others are excluded, by virtue of lack of technical expertise. At the same time, in-depth scholarship requires that very specialized subject matter is subjected to discipline-specific analysis, which of its very nature may be difficult for others, and even those in the field of bioethics itself, may struggle to understand. It is then the challenge of the whole field to ensure that these specialized analyses can be interpreted and understood by others. This is the task and mission of a journal such as the JBI. So it really should not be a case of "my way or the highway" in terms of the overall direction of the field but rather that the different academic disciplines allow for multifaceted consideration of the complex issues of our times. It is not so much a case of saying that Critical Bioethics, for instance, is the way the whole subject should go but rather to say that all methods have their place to make a contribution to a greater understanding. The application of a method that is clearly defined and understood by a craft group of academics, who accept common rules of engagement, which are themselves transparently communicated to the reader and have credibility within the parent discipline, makes a healthy contribution to knowledge that should stand apart from any attempt at methodological hegemony or academic imperialism.

Exhortations to holism and integration in a world that is beset by fragmentation, "splitting," and "Balkanization" are understood and necessary. Methods do not necessarily have a hierarchy in the "regimes of truth," but it is perhaps more a case of "horses for courses" in the common quest for the clarification of issues and ways to deal with difference in how to respond to them. If, for instance, a rigorous hermeneutic process of interpretation is needed, using wellestablished ways of analysing texts, then that surely need not contradict, for example, a sociological analysis of the same issue. However, it maybe that the hermeneutics reveal a truth that is misunderstood in society, just as the society influences the text in the first place. In some way, then, these things are circular-which is of course the etymological derivation of holism!

Our present issue reflects and illustrates this "dichotomy" to some degree. But it is more a case of horses for courses. There are a group of papers that address classical medical ethical issues such as professional responsibility and the duty to refer in cases of conscientious objection (Greenblum and Kasperbauer 2018), decision-making processes for dealing with possible return of genomic findings (Eckstein and Otlowski 2018), moral schism as a model for understanding parental experiences in neonatal ICU (Foe, Hellmann, and Greenberg 2018), debates about research participation, the therapeutic misconception, and human enhancement in the context of CRISPR technologies for military 
enhancement (Greene and Master 2018), and decisionmaking regarding apnoea testing for brain death (Lewis and Greer 2018).

Then there is a group of others that approach their topics from what could be argued is a more critical bioethical perspective including commodification and its impact on healthcare systems (Koplin 2018), the impact birth politics, changing meanings and value conceptions of embryos in the IVF space, and webs of social, bodily, and emotional relations on willingness to donate embryos for research in China (Rosemann and Luo 2018), epistemic arguments regarding responsibility for unhealthy behaviours (Levy 2018), and epistemic injustice and symbolic power in the context of patient complaints (O’Donovan and Madden 2018).

Common to a number of articles across both of these sets is discussion of the ethical complexities that arise when common dualisms begin to blur and bleed. This includes blurring of the personal and professional in the context of conscientious objection and the duty to refer (Greenblum and Kasperbauer 2018), between health and the market in relation to commodification of objects such as blood, gametes, and organs (Koplin 2018), between the research and clinical domains in the return of genomic findings (Eckstein and Otlowski 2018), and between health and enhancement when using CRISPR technologies in a military setting (Greene and Master 2018). Each of these articles reminds us of the need for critical reflection on taken-for-granted binaries that often underpin our ethical reasoning and it is here that an "opening up to scrutiny" from those outside the specialized niche can provide great insight.

In addition to the manuscripts outlined above, this issue also contains a symposium on collective representation in healthcare policy guest edited by Karin Jongsma, Nitzan Rimon-Zarfaty, Aviad Raz, and Silke Schicktanz, which they introduce in their lead essay (Jongsma et al. 2018). This interdisciplinary examination of the concept and practice of collective representation also ultimately breaks down the binary opposition of "All" and "One" to consider the continuum that in fact lies between.

\section{References}

Eckstein, L., and M. Otlowski. 2018. Strategies to guide the return of genomic research findings: An Australian perspective. Journal of Bioethical Inquiry 15(3): doi https://doi. org/10.1007/s11673-018-9856-7.

Foe, G., J. Hellmann, and R.A. Greenberg. 2018. Parental moral distress and moral schism in the neonatal ICU. Journal of Bioethical Inquiry 15(3): doi https://doi.org/10.1007/s11673018-9858-5.

Greenblum, J., and T.J. Kasperbauer. 2018. Forget evil: Autonomy, the physician-patient relationship, and the duty to refer. Journal of Bioethical Inquiry 15(3): doi https://doi. org/10.1007/s11673-018-9854-9.

Greene, M., and Z. Master. 2018. Ethical issues of using CRISPR technologies for research on military enhancement. Journal of Bioethical Inquiry 15(3): doi https://doi.org/10.1007 /s11673-018-9865-6.

Hedgecoe, A. 2004. Critical bioethics: Beyond the social science critique of applied ethics. Bioethics 18(2): 120-143.

Jongsma, K., N. Rimon-Zarfarty, A. Raz, and S. Schicktanz. 2018. One for all, all for one? Collective representation in healthcare policy. Journal of Bioethical Inquiry 15(3): doi https://doi.org/10.1007/s11673-018-9870-9.

Koplin, J.J. 2018. Commodification and human interests. Journal of Bioethical Inquiry 15(3): doi https://doi.org/10.1007 /s11673-018-9857-6.

Levy, N. 2018. Responsibility as an obstacle to good policy: The case of lifestyle related disease. Journal of Bioethical Inquiry 15(3): doi https://doi.org/10.1007/s11673-018-9860-y.

Lewis, A., and D. Greer. 2018. Medicolegal complications of apnoea testing for determination of brain death. Journal of Bioethical Inquiry 15(3): doi https://doi.org/10.1007/s11673018-9863-8.

O'Donovan, O., and D. Madden. 2018. Why do medical professional regulators dismiss most complaints from members of the public? Regulatory illiteracy, epistemic injustice, and symbolic power. Journal of Bioethical Inquiry 15(3): doi https://doi.org/10.1007/s11673-018-9869-2.

Rosemann, A., and H. Luo. 2018. Attitudes towards the donation of human embryos for stem cell research among Chinese IVF patients and students. Journal of Bioethical Inquiry 15(3): doi https://doi.org/10.1007/s11673-018-9862-9.

Twine, R. 2005. Constructing critical bioethics by deconstructing nature/culture dualism. Medicine, Health Care and Philosophy 8(3): 285-295. 